\title{
A Study on Perception and Understanding of Private Company Employees toward ASEAN Community in Thailand
}

\author{
Phieangruthai Tangthienthong and Khanchitpol Yousapronpaiboon
}

\begin{abstract}
This study examined the perception and understanding of private company employees toward ASEAN Community (AC), ASEAN Political-Security Community (APSC), ASEAN Economic Community (AEC) and ASEAN Socio-Cultural Community (ASCC) in Thailand. The objective was "to study how demographic factors can influence the perception and understanding of private company employees toward ASEAN Community in Thailand". This study adopted a quantitative research approach. All data were collected using a questionnaire survey. The 400 sets of questionnaires were filled by employees who work for a private company in Thailand. The data were tested using descriptive and inferential statistical analysis tools. The descriptive tool employed in this study included frequency, percentage, mean and standard deviation. Furthermore, the inferential statistical tools used in this research were independent t-test and One-way ANOVA. The result indicated that the perception and understanding of male and female toward APSC was significantly different ( $p$ value $=$ 0.003). The results also indicated that there was a significant difference on the perception and understanding of private company employees toward APSC among age groups ( $p$ value $=$ 0.003). Moreover, this study found that the perception and understanding of private company employees toward APSC (p value $=0.003)$, AEC $(p$ value $=0.000)$ and $\operatorname{ASCC}(p$ value $=$ $0.003)$ were significantly different among education levels.
\end{abstract}

Index Terms-ASEAN community, perception, understanding, Thailand.

\section{INTRODUCTION}

ASEAN or Association of Southeast Asian Nations was established under Thailand declaration on $8^{\text {th }}$ August 1967 [1]. At first, there were only five members which were Indonesia, Malaysia, the Philippines, Singapore and Thailand [1]. Later in 1997, the members of ASEAN has increased to 10 countries by adding Brunei Darussalam, Cambodia, Loa PDR, Myanmar and Viet Nam [1]. ASEAN Community has found under three main objectives, which are 1) to promote the development of economic, social and cultural richness in the region, 2) to maintain and stabilize economic situation in the region, and 3) to solve conflict circumstances in the region.

In order to become an effective ASEAN member, Thai people need to understand the root cause of conflict among member countries, history and culture of other countries. Thai people also need to be aware and give the importance to

Manuscript received April 10, 2014; revised June 17, 2014.

The authors are with College of Graduate Study in Management, Khon Kaen University. Bangkok, Thailand (e-mail: phiengruthai@yahoo.com, yousapro@yahoo.com). the development of cooperation of ASCC, as well as the development of economy in the country. Furthermore, ASEAN is an attractive emerging market that draws high attention from Thai investors who see an opportunity to expand their business. The understanding regarding background of $\mathrm{AC}$ is at great importance for Thai companies before making a decision to invest in any member countries. Onwimon (2013) states that most of Thais misunderstand about AEC and AC [2]. Thai people though they are going to enter AEC in 2015, but actually they are going to enter AC in 2015 [2]. AC means AEC, APSC and ASCC all together [2]. Besides, Siriwanbut (2012) who conducted a research with 2,170 students from leading university in Thailand found that these students have low level of understanding about ASEAN compare [3]. For example, only $30 \%$ of them know about ASEAN history and Flag, which is the smallest group compare to the rest of the ASEAN members [3].

For these reasons, this study aims to examine the perception and understanding of private company employees toward APSC, AEC and ASCC in Thailand.

This study contributes business in preparing and developing employee's competencies to be ready for the upcoming AC, improving competitive advantage, and developing national policy that is suitable when AEC is begun in year of 2015 .

\section{LITERATURE REVIEW}

\section{A. Perception}

Perception is a process in which an individual interprets subjects or objects by touching and using a personal sensory reception that is based on his/her ability and experience [4]. Perception depends on an individual's basic thought and emotion as well as the environment where a person stays at the time. A person cannot always perceive all information but only perceive the information based on his/her competence in perceiving and evaluating the information.

The perception processes comprise with four main steps. Step 1 is a conveyance step; the selective exposure of information which derives from stimulating things that impact five sensory areas (sight, hearing, smell, touch and taste) and selective attention. This information will be transferred from five sensory areas to brain and mind for interpretation. Step 2 is an elaborated step. This step is a prioritizing step in which detail of each information will be separated based on a specific emotion that happens from mind, knowledge and experience of an individual. Step 3 is a comprehension step, which means the step of understanding 
information. However, this does not mean that what people understand is correct or incorrect. The understanding is based on an individual's experience, norms and belief, which can be right or wrong. The final step is a retention step. At this step, an individual recognizes a subject or an object, which leads to a decision making process [4]. Furthermore, Yousapronpaiboon (2014) found that perceptions related to demographics in term of educations and ages. Especially, higher education can prepare themselves for AEC membership by offering superior service quality [5].

\section{B. Learning Process Related to Understanding}

Learning is a systematical process that leads to perception, understanding, attitude, value, norm, belief, willingness, need and emotion. Individuals have different needs and goals, which result in complexity of human behavior [6]. Most behaviors are the result from learning. For this reason, understanding learning process is essentially important for understanding human behavior.

Learning can be interpreted in many different ways. For example, learning is one type of human thinking processes that can change behavior of an individual from an original action to another action. This change is a result from experience and norms, not including the reaction from instinct or natural react [6].

Learning also means changing and enhancing competencies of an individual, which is a result from specific situation that set to help in learning. This change will appear and remain for quite a long period of time. Any changes that happen from learning process are different from growing and developing process [5]. Besides, learning is a process that lead to behavioral change by practicing and training [6]. Vitayaudom (2005) defined learning as a process of changing behavior, which depends on disciplinary practice and uncontrollable experience. The behavioral change can be adjusted or modified to become more or less effective [6]. Furthermore, learning process consists of three main components, which are knowledge, experience and association. Level of learning can also be classified into three main levels. These levels are cognitive change, affective change and behavioral change [4]. Sutharath (2009) stated that learning is one of human activities that can be seen everywhere. Moreover, learning is not a choice, yet it is an activity that cannot be avoided [7].Vera and Crossan (2003) agreed that learning is a process that consists of changing mind and behavior of an individual or a group of people. Learning is a result of either the understanding that leads to the implementation, or the implementation that lead to the understanding [8]. Fiol and Lyles (1985) argued that learning is related to a) cognitive understanding and new knowledge, b) new learning structure, and c) new learning system. Such as learning must be developed in form of activity. This can be concluded that learning is the process of bringing cognitive understanding and new knowledge together in order to connect new structure and new system together as a means to create new activity [9].

\section{Previous Studies}

Oulert (2012) studied the readiness of Sub-district Administrative Organization (SAO) toward AC [10]. The research was conducted in Ban Yang, Nakhon Thai district, Phitsanulok province. Oulert (2012) examined the level of knowledge and understanding of people in Ban Yang toward the readiness of becoming AC. There were 400 samples and 87 local government agents completed the questionnaire. The research focused on five perspectives, which were economic, social, cultural, educational and public health. The results showed that the preparation toward upcoming AC under social and cultural perspectives were in the middle level (mean = 2.67). Nevertheless, the English language preparation was fairly low $($ mean $=2.09)$ [10].

In addition, Issarakoul Na Ayuttaya (2013) who studied perception, understanding and attitude toward AC among Thais people [11]. The results indicated that most people have low perception about this unification between 10 countries in ASEAN. For example, less than half of the samples in rural area did not know an exact number of ASEAN members. This might be a result from communication problems. These people do not have access to up-to-date information due to unavailability of communication technologies. The study also examined the attitude of Thailand people toward the integration of countries in ASEAN. The results showed that Thailand people do excited about AC. They are eager to learn new things and to prepare themselves for this event [11]. However, the respondents agreed that they are afraid that Thailand will progress behind the other members in AC [11]. Issarakoul Na Ayuttaya (2013) also added that most Thai people do know that Thailand is a member of ASEAN, which will be started in 2015. However, they do not know what AC is and what benefits of becoming AC [11].

Jaidee. (2013) studied an information access and understanding perceived by leader personnel and Community leaders toward ASEAN [12]. The study was conducted in Nakornrajsrima province. There were 120 respondents completed the questionnaire and participated in a focus group [12]. The result indicated that leaders of the Community and local government agents have medium knowledge toward ASEAN and low level of information access via media [12].

Pattum and Sutamaung (2013) conducted a research on perception of working people in Bangkok toward the opening of AEC [13]. Pattum and Sutamaung (2013) collected data from 400 people who work in Bangkok using questionnaire as a research instrument [13]. The data were collected from the respondents of 10 districts in Bangkok which were, Minburi, Buengkum, Bangkapi, Lardpraow, Donmueng, Bangna, Saton, Bangruk, Phayathai, and Bangkea [13]. They found that occupation, education, income levels can affect to the perception of working people in Bangkok about opening AEC differently [13]. They also found that internal factor (learning factor) can significantly influence the perception of working people in Bangkok toward the upcoming AEC [13]. Furthermore, external factors (government policies) also significantly influences the perception of working people in Bangkok toward the same event [13]. The other factor that Pattum and Sutamaung (2013) found that it can significantly influence perception of working people in Bangkok toward the upcoming AEC was economic factors [13].

Kongtem (2013) investigated how university students from different faculties prepare themselves for the upcoming 
ASEAN Community in terms of knowledge, competency and attitude [14]. Kongtem (2013) adopted questionnaire as a research instrument and collected the data from 1,540 students who study in Phetchabun Rajabhat University [14]. The samplings have been separated into five groups, which are student from faculty of education, faculty of humanities and social sciences, faculty of science, faculty of management science, and faculty of agricultural technology. The result indicated that students who study in different faculties have different aspects of readiness toward ASEAN Community in terms of knowledge, competencies and attitude [14].

\section{Research Framework and Hypotheses}

There are three hypotheses developed under this study as showed in Fig. 1. These hypotheses are H1: there is a significant difference in perception and understanding toward APSC, AEC, ASCC and AC between male and female employees in a private company; $\mathrm{H} 2$ : there is a significant difference in perception and understanding toward APSC, AEC, ASCC and AC among employees in a private company who have different age levels; H3: there is a significant difference in perception and understanding toward APSC, AEC, ASCC and AC among employees in a private company who have different education levels.

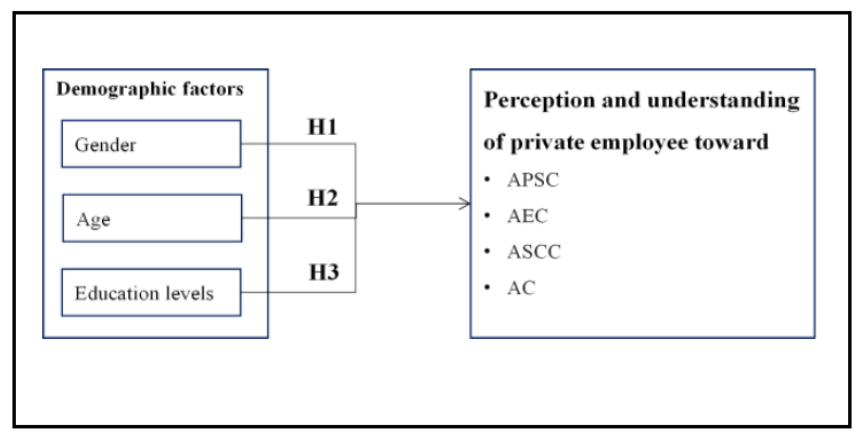

Fig. 1. Research framework

\section{METHOD}

This study adopted a quantitative approach by employing self-administrative questionnaire survey as the research instrument. All data were collected from 400 employees who work for a private company in Thailand. The analysis tools adopted in this study were descriptive and inferential statistical tools. Hypothesis 1 was tested using independent t-test, while hypotheses 2 and 3 were tested using One-way ANOVA.

\section{RESUlTS}

\section{A. Descriptive Results}

There were $164(41 \%)$ of male and $239(59 \%)$ of female respondents who participated in the survey. Most of the respondents or $66.8 \%$ of them earn bachelor's degree, while only $3 \%$ of the respondents earn Doctoral or $\mathrm{PhD}$. There were $14.3 \%$ of the respondents whose education background are lower than bachelor's degree, and $18.3 \%$ of the respondents earn master's degree. Furthermore, more than
$50 \%$ of the respondents are between $25-35$ years old (55\%). Less than $10 \%$ of the respondents are older than 45 years old. About one in fourth of the respondents are between 36-45 years old.

\section{B. Hypotheses Testing Results}

The results indicated that there was a significant difference in perception and understanding of APSC between male and female respondents who work for a private company ( $\mathrm{p}$ value $=0.003)$. However, there was no significant difference in perception and understanding of AEC, ASCC and AC between male and female respondents who work for a private company. Therefore, hypotheses 1 was partly supported (Table I).

TABLE I: HYPOTHESIS 1

\begin{tabular}{|c|c|c|c|c|}
\hline \multirow{2}{*}{$\begin{array}{c}\text { Perception and } \\
\text { understanding toward }\end{array}$} & \multicolumn{2}{|c|}{ Mean } & \multirow[b]{2}{*}{$\mathrm{t}$} & \multirow[b]{2}{*}{ Sig. } \\
\hline & Male & Female & & \\
\hline APSC & 3.43 & 3.12 & -3.011 & $.003^{*}$ \\
\hline $\mathrm{AEC}$ & 3.35 & 3.24 & -0.869 & .366 \\
\hline ASCC & 3.30 & 3.17 & -1.099 & .273 \\
\hline $\mathrm{AC}$ & 3.36 & 3.18 & -1.728 & 0.085 \\
\hline \multicolumn{5}{|c|}{ *Significance at 0.05} \\
\hline
\end{tabular}

The results also indicated that there was a significant difference in perception and understanding of APSC among age groups of employees who work for a private company ( $p$ value $=0.003$ ). Similar to hypotheses 1 , the results showed that there was no significant difference in perception and understanding of AEC, ASCC and AC among age levels of employees who work for a private company. Thus, hypotheses 2 was partly supported as showed in Table II.

TABLE II: HYPOTHESIS 2

\begin{tabular}{|c|c|c|c|c|c|}
\hline \multicolumn{2}{|c|}{$\begin{array}{c}\text { Perception and } \\
\text { understanding toward }\end{array}$} & APSC & $\mathrm{AEC}$ & ASCC & $\mathrm{AC}$ \\
\hline \multirow{6}{*}{ 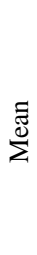 } & $25-30$ years & 3.13 & 3.30 & 3.26 & 3.23 \\
\hline & $31-35$ years & 3.08 & 3.20 & 3.12 & 3.13 \\
\hline & $36-40$ years & 3.45 & 3.42 & 3.30 & 3.39 \\
\hline & 41-45 years & 3.36 & 3.34 & 3.29 & 3.33 \\
\hline & $46-50$ years & 3.70 & 3.33 & 3.29 & 3.44 \\
\hline & $\begin{array}{l}\text { More than } 50 \\
\text { years }\end{array}$ & 3.85 & 3.19 & 3.10 & 3.38 \\
\hline & $\mathrm{F}$ & 3.63 & 0.37 & 0.34 & 0.755 \\
\hline & Sig. & $0.003 *$ & 0.873 & 0.891 & 0.583 \\
\hline \multicolumn{6}{|c|}{ *Significance at 0.05} \\
\hline
\end{tabular}

Additionally, the results in Table III indicated that there was significant difference in perception and understanding of APSC, AEC, ASCC and AC among education levels of private company employees. As expected Doctoral respondents is a group of people who are likely to have wide knowledge regarding the country's direction and thus have the highest perception and understanding toward APSC, AEC, ASCC and AC. In contrast, the group of respondents whose education level are lower may have lesser knowledge regarding the country's situation and therefore having a lower level of perception and understanding toward the upcoming AEC. This implies that education is important for people to perceive and understand about AC. Thus, hypotheses 3 was fully supported. 
TABLE III: HYPOTHESIS 3

\begin{tabular}{|c|c|c|c|c|c|}
\hline \multicolumn{2}{|c|}{$\begin{array}{c}\text { Perception and } \\
\text { understanding toward }\end{array}$} & APSC & $\mathrm{AEC}$ & ASCC & $\mathrm{AC}$ \\
\hline \multirow{4}{*}{$\sum_{\Sigma}^{\tilde{E}}$} & $\begin{array}{l}\text { Lower than } \\
\text { Bachelor }\end{array}$ & 3.09 & 3.06 & 3.08 & 3.08 \\
\hline & Bachelor & 3.18 & 3.20 & 3.14 & 3.17 \\
\hline & Master & 3.57 & 3.73 & 3.56 & 3.62 \\
\hline & $\mathrm{PhD}$ & 4.43 & 4.18 & 4.67 & 4.43 \\
\hline \multicolumn{2}{|r|}{$\mathrm{F}$} & 4.747 & 6.150 & 4.612 & 5.728 \\
\hline \multicolumn{2}{|r|}{ Sig. } & $0.003 *$ & $0.000 *$ & $0.003^{*}$ & $0.001 *$ \\
\hline \multicolumn{6}{|c|}{ *Significance at 0.05} \\
\hline
\end{tabular}

\section{DISCUSSION}

The result found in this study indicated that education difference can result in perception and understanding differences in the subjects of APSC, AEC, ASCC and AC. Moreover, the respondents with lower education level have less perception and understanding toward APSC, AEC, ASCC and AC. This result is supported by Pattum and Sutamaung (2013) who found that education difference impacted perception of people in Bangkok toward AEC [13]. In other words, people with different education levels perceive AEC in a dissimilar way. Pattum and Sutamaung (2013) found that people whose education are Master or higher have higher level of perception toward trading in AEC than people whose education are lower than Bachelor degree [13]. However, such differences determined by educational level is not always the case. The finding related education in this study is different with what Jaidee (2013) has found in her research on information access and understanding toward ASEAN [10]. Jaidee (2103) was collected from the groups of respondents whose highest education level was primary school, but were leader personnel and leaders of sub-district administrative organization at the time. Up to $94 \%$ of samples have medium to high levels of understanding toward the overall background and direction of AC. Occupation could be a reason that explain this difference. This study collected the data from only private company employees whose job may not involve directly with AEC direction, whereas the samples from Jaidee (2013) studied were local government authority whose job is directly involve the country's policy and direction such as the upcoming AEC. These people work for the government and thus should have wide knowledge and awareness about what will be happened when AEC is established in 2015. Besides, a research by Kongtem (2013) supported the idea that different occupations can lead to different aspects of readiness toward ASEAN Community. Kongtem (2013) conducted the research with university students from various fields of study [14]. Kongtem (2013) found that students from different faculties have prepared themselves differently toward the upcoming ASEAN Community in many areas such as knowledge, competencies and attitude [14]. This can be implied that people in different fields of work can have different levels of understanding and perception toward ASEAN Community. Therefore, level of education may not be a significant factor that determines Thai people's perception and understanding toward $\mathrm{AEC}$, if their job is directly related to the event.

\section{CONCLUSION}

In summary, this study found that the perception and understanding toward APSC can be varied by genders, age groups and education levels. This research also indicated that the perception and understanding toward AEC, ASCC and AC can be varied by education levels. Specifically, doctoral respondents seem to have higher level of perception and understanding than the other groups of respondents who have a lower education level.

According to the result found in this study, it can be implied that Thai government needs to develop different communication strategies to increase perception and understanding on APSC for different genders, age groups and education levels. The results can also imply that lower education level people need more support to improve their perception and understanding toward APSC, AEC, ASCC and $\mathrm{AC}$. For this reason, the government or related parties should consider developing more effective communication techniques or strategies to increase perception and understanding toward AC among Thai people who have low education. This should consequently help the country stay more competitively in the AEC.

\section{REFERENCES}

[1] ASEAN (2012). The Founding of ASEAN. [Online]. Available: http://www.asean.org/asean/about-asean/history

[2] The Government Public. (2013). ASEAN Knowledge. [Online]. Available: http://www.aseanthai.net/special-news-detail.php?id=21

[3] P. Siriwanbut, ASEAN Residents Ready for ASEAN Community, Mahidol University, Thailand.

[4] C. Samoerjai, Consumer Behavior, $1^{\text {st }}$ ed, Thailand, Thailand Se-Education Publishing, 2007, ch. 4, pp. 66-72.

[5] K. Yousapronpaiboon, "Servqual: measuring higher education service quality in Thailand," Procedia-Social and Behavior Sciences, vol. 116, pp. 1088-1095, 2014.

[6] V. Vitayaudom, Organization Behavior, $5^{\text {th }}$ ed, Thailand, Thailand: Thanarath Publishing, 2005, ch. 7, pp. 123-124.

[7] Y. Sutharath, Organization for Learning, $1^{\text {st }}$ ed, Thailand, Thailand: Chulalongkorn University Publishing, 2009, ch. 2, pp. 29.

[8] D. M. Vera and M. M. Crossan, "Reconciling the tentions in learning and knowledge," in Proc. Organization Learning and Knowledge: $5^{\text {th }}$ International Conference, Lancaster University, UK, 2003.

[9] C. M. Fiol and M. Lyles, "Organizational learning," Acadamy of Management Review, vol. 10, no. 4, pp. 803-813, 1985.

[10] V. Oulert, "The readiness of subdistrict administrative organization (SAO) toward ASEAN community: a case of ban yang, Nakhon Thai district, Phitsanulok province," Master, Dissertation, Dept. Public Administration, Khon Kaen Univ., Khon Kaen, Thailand, 2012.

[11] N. Pattarasitthisakul. (2013). Survey on how Thai people know about ASEAN. The MCOT Public Company Limited. [Online]. Available: http://www.mcot.net/site/content?id=5214a18f150ba09410000101\#.U zeLIihrG00

[12] D. Jaidee, "Guideline for capacity building related to ASEAN Community among local personnel and community leaders of Nongbuanoi Tambon administration organization, Sikhiu District, Nakhonratchasima Province," in Proc. Khon Kaen University Graduate Research Conference, pp. 1683-1691, 2013.

[13] S. Pattum and K. Sutamaung, "Perception of opening Asian economic community by Thai government in working people in Bangkok," Money Investment Marketing and Business Management Magazine, vol. 3, no. 4, pp. 490-507, 2013.

[14] S. Kongtem, "The study of readiness to ASEAN community of students in Phetchabun Rajabhat University," master thesis, faculty of education, Phetchabun Rajabhat Univ., Phetchabun, Thailand, 2013. 


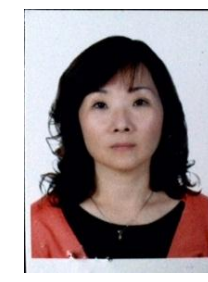

construction.
Phieangruthai Tangthienthong was born in Thailand on $2^{\text {nd }}$ of December 1969. Phieangruthai Tangthienthong finished high school from Santiratwitthayalai School, bachelor degree in BBA from Assumption University in Thailand and currently, studying MBA at College of Graduate Study in Management, Khon Kaen University.

Phieangruthai Tangthienthong is now working as accounting and financial manager at Numkrai Universal

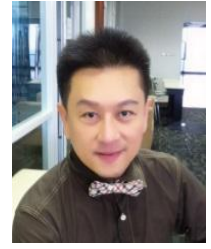

Khanchitpol Yousapronpaiboon served as an assistant professor of marketing at College of Graduate Study in management in Khon Kaen University for 12 years, where he taught marketing management and service marketing management courses at master and doctoral levels. He received an excellence teaching award of Khon Kaen University in 2003. He gained his DBA from Nova Southeastern University of the $H$. Wayne Huizenga's school of business \& entrepreneurship FL., USA. He worked in Bangkok Bank Public Company Limited for 10 years. He is the honorary advisor; the secretary of the senate standing committee on education; and sub-standing committee on the follow up and evaluation preparation of ASEAN community, the senate standing committee on education in Thailand. He is also a part-time lecturer of marketing management and service marketing management courses at Chiang Mai University and Ubon Ratchatani University in Thailand. 